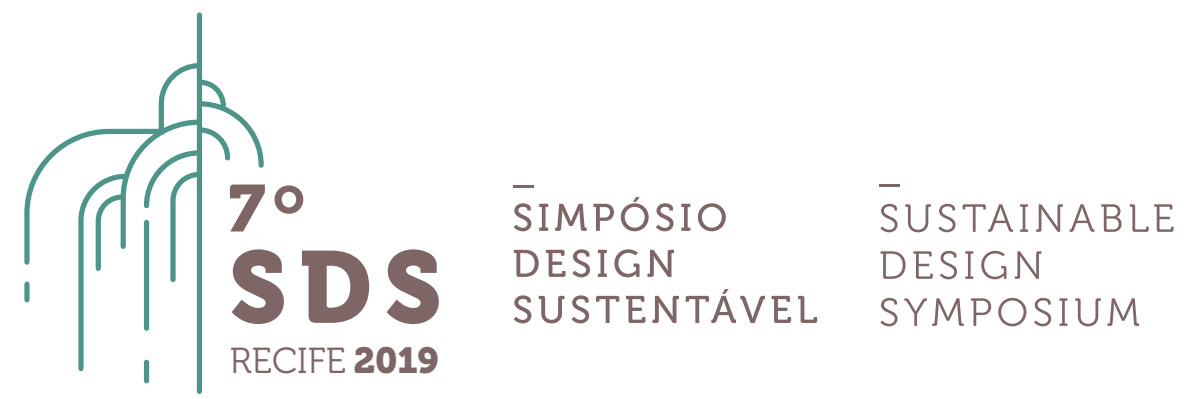

\title{
Implicações ambientais na Fabricação Digital: Insustentabilidade no processo da CNC Fresadora
}

\author{
Júlia Souza Abrão ${ }^{1, a}$, Viviane G. A. Nunes ${ }^{2}$ \\ ${ }^{1}$ Universidade Federal de Uberlândia, PPGAU/FAUED, juliaabraoufu@gmail.com \\ ${ }^{2}$ Universidade Federal de Uberlândia, PPGAU/FAUED, viviane.nunes@ufu.br
}

\begin{abstract}
Resumo. A recente revolução nos processos de fabricação que se tornaram digitais, com máquinas controladas por parâmetros computacionais, contribui para o lançamento do software de modelagem, no qual a criação se tornou irrestrita e muito mais complexa. Com isso, a relação entre design e produção é reconfigurada, onde o designer agora controla todo o processo, desde a criação até a fabricação. No entanto, a Fabricação Digital (FD) também apresenta muitos desafios a serem superados, principalmente aqueles relacionados ao meio ambiente. No caso da produção das CNC Fresadoras, o alto volume de resíduos resultantes de projetos com alta complexidade formal, sem possibilidade de reutilização, é motivo de preocupação. Esta pesquisa de mestrado visa investigar as relações entre projeto e produção, especificamente relacionadas aos processos do CNC. Em sua fase inicial, o objetivo principal é definir diretrizes projetuais para orientar jovens designers na etapa do processo de projeto, a fim de alcançar soluções mais integradas, sistêmicas e ecoeficientes. A base teórica preliminar é: Fabricação Digital (KOLAREVIC, 2005; OOSTERHUIS, 2005; OXMAN, 2006; PUPO, 2009; HAUSCHILD; KARZEL, 2011; BALLERINI, 2017); Design e processos de fabricação (DESIGN Q \& A, 1972; HEEMANN, 2008; BLIKSTEIN, 2013); Sustentabilidade (MANZINI e VEZZOLI, 2008, CACCERE, 2017). A pesquisa é orientada por metodologia qualitativa, com abordagem exploratória e utiliza o método de pesquisa-ação, combinando etapas teóricas e práticas. Considerando que no Brasil as metodologias voltadas para a fabricação digital ainda são incipientes, a esperança é que os resultados da pesquisa possam apoiar práticas de Projetos novos e mais sustentáveis, dentro e fora das universidades.
\end{abstract}

Palavras-chave. Fabricação Digital; Processo de projeto; Sustentabilidade; Ética projetual; CNC Fresadora. 


\title{
1 Introdução
}

O avanço da tecnologia vem progredindo cada vez mais, difundindo-se entre diversas áreas, reconfigurando a relação entre criação de projeto e produção (PUPO, 2009) e induzindo assim, a um novo modo de projetar, principalmente no campo do design. Nesse cenário, um processo inovador de criação se constituiu pela união dessa nova tecnologia aliada aos novos campos computacionais, os chamados softwares de modelagem, trazendo a possibilidade de criação e produção de projetos altamente complexos. A fabricação, agora, ocorre digitalmente controlada por parâmetros computacionais, denominada Fabricação Digital, com a possibilidade de fabricação de peças bidimensionais e até tridimensionais.

Esse novo método de fabricação, denominado file-to-factory (do arquivo para a fábrica), subtrai etapas de representações entre o projetista e o produto final (BARBOSA NETO et al., 2014). Neste processo, não apenas o projeto é desenvolvido digitalmente, mas também a sua produção ocorre pelo processo de fabricação digital, possibilitando o designer controlar todo o processo, desde a criação até a produção.

Essa manufatura traz grandes vantagens em sua utilização, trazendo benefícios em várias áreas, tais como: saúde, economia, educação, dentre outros. Contudo, a fabricação digital apresenta também muitos desafios a serem superados, tendo em vista, principalmente, questões relacionadas ao meio ambiente. A grande preocupação está relacionada ao alto volume de descarte de material que ocorre na fabricação subtrativa. Em virtude da alta complexidade das formas, mesmo havendo planejamento dos cortes, há também a geração de peças pequenas com pouco reaproveitamento e que resultam em sérios impactos ambientais.

O referencial teórico desta pesquisa baseia-se nos conceitos de Fabricação Digital (de forma ampliada), de Processo de Projeto e Sustentabilidade, tendo como aspectos específicos a Manufatura Subtrativa e de Diretrizes de Projeto Sustentáveis.

A partir deste panorama, a pesquisa tem como principal objetivo desenvolver diretrizes projetuais para orientar processos de fabricação digital, visando a um modelo de produção mais sustentável. Para tanto, poderão ser estabelecidos comparativos entre as estratégias de projeto e produção, em estudos específicos, tanto do ensino do projeto do produto quanto das tecnologias produtivas digitais.

\section{Metodologia}

A pesquisa é orientada por metodologia qualitativa, de caráter exploratório e utiliza o método da pesquisa-ação. De acordo com a definição por Thiollent (1988):

\begin{abstract}
A pesquisa ação é um tipo de investigação social com base empírica que é concebida e realizada em estreita associação com uma ação ou com a resolução de um problema coletivo no qual os pesquisadores e os participantes representativos da situação ou do problema estão envolvidos de modo cooperativo ou participativo.
\end{abstract}

O processo de pesquisa se dará por meio de três etapas fundamentais: (i) A primeira etapa (teórica) se realizará por meio de levantamento e revisões bibliográficas relacionadas ao tema, dentre os assuntos principais: fabricação digital, sustentabilidade e processo de projeto de produto. E também contará com estudos de caso para a análise de pesquisas já realizadas, podendo assim evitar erros já ocorridos e trazer elementos bem sucedidos como referência para este projeto; (ii) A segunda etapa se fundamenta por meio da Pesquisa-Ação, contendo em sua estrutura estudos de campo dentro dos cursos da Universidade (UFU), que englobam em sua ementa, disciplinas relacionadas ao processo de projeto, com finalidade de estudo e análise de 
como esse processo de criação se realiza em uma visão interdisciplinar. Esta etapa conta também com a proposta de dois workshops para o desenvolvimento de projetos: 1) o workshop inicial com objetivo de análise dos projetos criados para serem produzidos nas manufaturas digitais, modelagem/fabricação dos produtos que foram desenvolvidos e posteriormente a análise dos resultados comparativos entre estratégias de projeto, a fim de definir diretrizes de projeto mais adequadas de fabricação digital, utilização desse material para a construção de um manual, e 2) a realização do workshop final com a implementação dos métodos em sua estrutura didática, passando novamente pelas etapas de modelagem/fabricação; (iii) A terceira etapa teórica, terá como objetivo a análise final entre esses dois workshops para analisar a viabilidade desse manual e qual o grau de impacto que ele trouxe na etapa de projeto.

\section{Revisão Bibliográfica e Discussão}

A fundamentação teórica parte dos principais temas definido como: Fabricação digital (KOLAREVIC, 2005; OOSTERHUIS, 2005; OXMAN, 2006; PUPO, 2009; HAUSCHILD; KARZEL, 2011; BALLERINI, 2017), Processo de projeto e fabricação (DESIGN Q \& A, 1972; HEEMANN, 2008; BLIKSTEIN, 2013), Sustentabilidade (MANZINI, 2008; VEZZOLI, 2008; NUNES, 2008; CACCERE, 2017). No decorrer do trabalho serão selecionados outros autores para subsidiar a pesquisa.

\section{Fabricação Digital}

A fabricação Digital tem sua fase de disseminação a partir de 1980, tendo como start a democratização das novas máquinas e das plataformas de código aberto, ocorrendo uma mudança significativa nos processos convencionais de produção, passando para a produção digital, abrangendo o design e a materialidade (BALLERINI, 2017).

Na visão de Mitchell (KOLAREVIC, 2005), têm ocorrido vários acontecimentos no campo da tecnologia de fabricação, nos quais as máquinas são controladas por computador. Essa tecnologia entendida pela sigla CNC (Controle Numérico Computadorizado), derivadas do binômio CAD/CAM (BALLERINI, 2017), vem gradualmente surpreendendo em todas as escalas, desde as nano-escalas (átomos), passando pela escala de design de produtos, chegando até a escala da arquitetura.

Nitidamente há um significativo grau de inovação, levando em consideração o domínio dos sistemas de suporte computacional empregado para explorar ideias de design (KOLAREVIC, 2005).

A Fabricação Digital (FD) surge neste contexto, possibilitando a criação de desenhos em 2D/3D por meio dos novos softwares, e uma série de ferramentas e tecnologias para a execução de projetos. E, como consequência, a FD proporciona uma aproximação do projetista com o processo de fabricação (GERSHENFELD, 2012 apud CACCERE, 2017). Nesse cenário ressurge o paradigma do mestre construtor, no qual o projetista está totalmente envolvido desde a produção e construção de uma forma (KOLAREVIC, 2005).

É importante destacar que evolução de técnicas está voltada para a melhoria dos processos produtivos e consequentemente do aumento do capital, deixando de lado a melhora de condição de trabalho e ganhos para o trabalhador. Nesse cenário há um fortalecimento de sistemas, enfraquecendo o operário, e tendo a ausência do saber como consequência (BALLERINI, 2017).

A inserção do computador no âmbito de produção industrial foi considerada como uma revolução industrial no período moderno. Esta promoveu uma evolução da linguagem computacional maquinária paralelamente com a tecnologia da informática, ocasionando a interatividade entre projetista, a codificação digital e a fabricação. No cenário da Fabricação digital, ocorre a ruptura do intervalo entre o digital e o material (BALLERINI, 2017). 
Segundo Meredith (2008), o designer contemporâneo está aí inserido, ou seja, projeta tendo em mente a fabricação, contribuindo para o surgimento do termo Design to production. Considerando o atual processo de construção, a inserção do design digital e dos utensílios de fabricação, ocorre um trânsito de informações desde a concepção até a criação do projeto.

Como dito anteriormente, o processo file-to-factory subtrai etapas de representações entre o projetista e produto final (BARBOSA NETO et al., 2014), sendo projeto e produção desenvolvidos com suportes de processos digitais. Para Oosterhuis (2005), o file-to-factory se realiza na combinação das etapas de projeto e da fabricação, envolvendo nesse processo a troca de informações entre softwares de modelagem tridimensional para uma máquina de fabricação digital, fases estas baseadas em princípios computacionais.

Para Oxman (2006), devido a essa evolução tecnológica, surgem novas funções para o designer contemporâneo, que propiciam maior autonomia para o projetista, interagindo e moderando processos e mecanismos gerativos e performativos. Neste contexto a informação passa a ser um "novo material" para o projetista.

\section{Tipologias de Fabricação Digital e Maquinários}

Estas novas máquinas podem ser distinguidas pelo processo de fabricação, trazendo possibilidades para exploração de novas geometrias. De acordo com Kolarevic (2005), esses meios de fabricação são definidos como:

- Fabricação subtrativa: definida pelo desbaste de volume especificado de material sólido, pelo processo de fresamento ou de eletro-química (cortadora a laser). 0 processo de fresamento é determinado pela quantidade de eixos, podendo realizar cortes 2D, atingindo até rebaixos do material, modelos 3D.

- Fabricação aditiva: ocorre pela adição de material de camada em camada, podendo ser chamada também de prototipagem rápida. Essa tecnologia segue o princípio de um modelo digital sólido que é dividido em camadas bidimensionais para a fabricação.

- Fabricação Formativa: nessa fabricação, forças mecânicas, calor ou vapor são aplicadas a um material, para se conseguir a forma desejada, sendo por meio de modelagem ou deformação.

Esses meios de manufatura podem confeccionar tanto o projeto inteiriço, quanto a fabricação por partes, para serem montadas em posteriormente.

Os processos de fabricação digital contam com diversas máquinas, dentre elas: CNC (Controle Numérico Computadorizado) precast concrete elements (concreto pré-moldado), 3D printing (impressora 3D), CNC laser cutting (corte a laser), CNC jetcutting (corte a jato), CNC hot wirecutting (corte a quente), CNC milling (moagem), dentre outras (HAUSCHILD; KARZEL, 2011).

Aproximando para o campo do design, as máquinas mais próximas e mais usadas em escala de produto são: impressão 3D, Cortadora a laser e a CNC Milling e a CNC Router. Segundo Seely (2004):

- A CNC Router é utilizada para o fresamento de formas bidimensionais em materiais como folhas de madeira, compensado e espumas.

- Já a CNC Milling é voltada para a criação de formas tridimensionais a partir de um bloco de material, tais como madeira, metal, plástico e espumas.

Ambas as máquinas funcionam com o método subtrativo e a distinção se dá pelos eixos em 
que a máquina se movimenta. Em relação ao maquinário que possui em sua estrutura fresas de três, quatro ou cinco eixos, tem a capacidade para conceber projetos tridimensionais (PUPO, 2009).

Na versão de manufatura subtrativa, há uma gama de materiais que podem ser utilizados nessa fabricação; porém, a maior preocupação em relação a essa tipologia é relacionada ao alto desperdício de matéria prima, ocorrido pelo desbaste da peça durante a fabricação (BALLERINI, 2017).

- A cortadora a laser (CNC laser cutting) é considerada a mais comum entre todas as outras manufaturas. Seu processo se realiza através de um conjunto de espelhos contidos em sua estrutura que direcionam o feixe de laser no material utilizado, e a partir da potência pré-configurada do laser e a espessura da matéria prima, ocorre a queima/gravação ou até cortando o material (POTTMANN et al, 2008 apud PUPO, 2009). Essa máquina trabalha com materiais como: madeira, papel, papelão, aglomerado de madeira e plástico (SEELY, 2004).

- $E$, por último, a Impressora 3D (3D printing), relacionada ao campo da prototipagem rápida, tem como princípio a manufatura aditiva, que por meio de um cabeçote de impressão, deposita esse material por camadas sucessivamente até que o objeto esteja completo (SEELY, 2004). Para que esse processo de camadas ocorra, o software possui uma ferramenta que é usada para a geração de divisões horizontais do projeto digital e envia essas informações computacionais para a máquina (PUPO, 2009).

Esse modo de produção contempla diferentes materiais a serem depositados, dentre eles: plástico, chocolate, cerâmica, moléculas, entre outros. A matéria prima mais habitual é referente aos plásticos de engenharia como o ABS (Acrilonitrila butadieno estireno) e PLA (Ácido polilático) (VOLPATO, 2007 apud BALLERINI, 2017).

Pode-se observar que Fabricação Digital trouxe mudanças significativas no modo de projetar e produzir, possibilitando discutir questões importantes e viabilizando inovações; por outro lado, a FD também desperta algumas preocupações, especialmente aquelas relacionada são meio ambiente. Vários autores (MANZINI, 1993; MANZINI e VEZZOLI, 2008; NUNES, 2008, BALLERINI, 2017, e outros) têm discutido a imprescindível necessidade dos processos projetuais gerenciarem de forma eficiente o uso dos recursos naturais, respeitando os limites do planeta e seu ciclo de vida.

É importante ressaltar que, estar ciente da capacidade e limitações de fabricação e disponibilidade de maquinário, direciona os designers em suas etapas de criação a projetar visando às capacidades dos maquinários. Como resultado, ocorre uma relação intensa entre os projetistas e os processos de produção (KOLAREVIC, 2010 apud BARBOSA NETO et al., 2014).

\section{Processos criativos e forma complexas}

Essa tipologia de manufatura promove liberdade de criação, um alto nível de complexidade de projeto. De acordo com Kolarevic (2005), esse fascínio pelas formas ocorre por meio dos softwares de modelagem tridimensionais, como exemplo o software Rhino, baseados em NURBS (Non-Uniform Rational B-Splines), que possibilitam a formação de curvas variadas e superfícies paramétricas e o desenvolvimento de inúmeras formas complexas (PUPO, 2009). 
Figura 1 - Complexidade de Formas
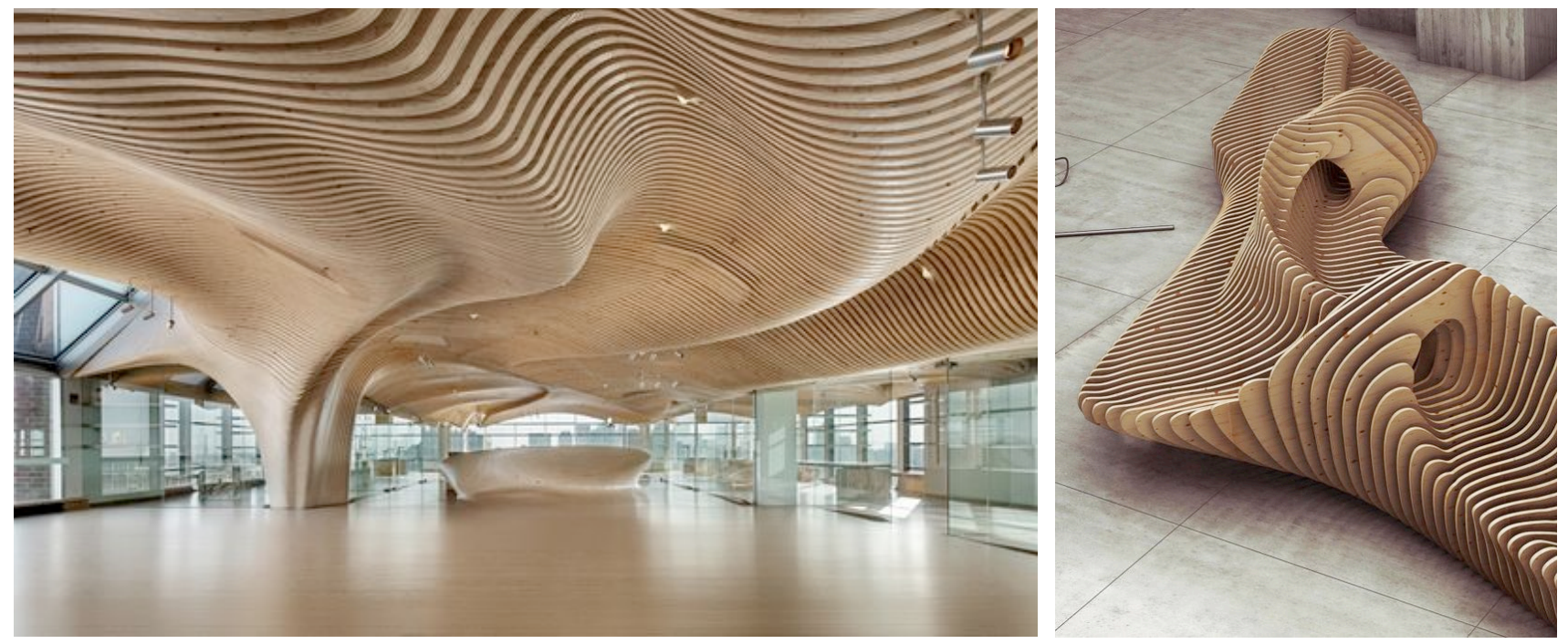

Fonte: Pinterest (2019)

Ainda sobre essa complexidade, as novas formas geométricas denominadas "freeform geometries" (geometrias livres), elevam a importância da prototipagem rápida e a fabricação digital nas quais, por meio dos inputs e outputs digitais (entrada e saída de informações), são capazes de gerar formas tangíveis, precisas, compostas de geometrias complexas. Ademais, proporcionam maior flexibilidade e novas possibilidades de projeto (PUPO, 2009).

Nesses softwares de modelagem, diretrizes de projeto são codificadas, construindo um conjunto de dados (projeto) que pode ser alterado sempre que necessário a fim de se obter um melhor resultado. $O$ conceito de mass-customization (customização em massa) pode ser inserido nesse contexto, uma vez que contribui para produção (controlada digitalmente) específica/personalizada para cada cliente (HAUSCHILD; KARZEL, 2011). Uma tipologia de customização em massa (onde o projeto é modificado) é fruto dos softwares paramétricos, conhecidos também pelo termo "geometria associativa" (BARBOSA NETO et al., 2014).

Sobre os softwares de parametrização, Oosterhuis, 2005 afirma que:

[...] Cada vez que um parâmetro é alterado, o modelo se regenera para refletir o novo valor. [...] O modelo paramétrico representa a configuração de um meta design que permite um design reconfigurável.

A produção customizada permite proporcionar para o cliente um sentimento de satisfação maior sobre o produto e, consequentemente, colabora para a ampliação do ciclo de vida dos produtos. Essa afirmação parte do pressuposto que, quando se tem acesso ao arquivo do produto modelado e as máquinas adequadas, tem-se a possibilidade de reproduzir o produto quantas vezes for almejado (CACCERE, 2017).

De acordo com Blikstein (2013), a Fabricação Digital acelera o ciclo de invenção do design, transformando uma ideia em um produto, tendo a possibilidade de redesenho em um mesmo intervalo de tempo. $O$ autor ressalta também a importância do educador no processo de ensino ao utilizar a máquina como ferramenta de exploração de novas formas de interações humanas.

Além de facilitar os processos produtivos, a fabricação digital também possibilitou o surgimento de novos segmentos de mercado como, por exemplo, a criação dos FabLabs: espaços físicos que contém máquinas de fabricação digital, computadores e softwares, com objetivo de viabilizar a construção de um objeto, desde da modelagem digital até a materialização. Esses 
locais demonstram competência para capacitar indivíduos, até criar dispositivos para si mesmos (ORCIUOLI, 2012).

Destaca-se que a possibilidade de capacitação incentiva o processo de criação de novas empresas criativas, originadas por pessoas que buscam um espaço no mercado, e que podem até mesmo atuarem em setores menos favorecidos da sociedade.

Esse modo de fabricação inovadora integra o consumidor de baixa renda no processo de desenvolvimento de produtos (de custos menores), determinando as principais características que o artefato deve possuir, visando suas necessidades individuais (DIEGEL et al., 2010 apud CACCERE, 2017), a fim de gerar um produto acessível economicamente.

\section{Implicações da Fabricação Digital}

Apesar de apresentar grandes vantagens em sua utilização, a fabricação digital apresenta também muitos desafios a serem superados, tendo em vista, principalmente, questões relacionadas ao meio ambiente, como mencionado.

O termo Rebound Effect (efeito bumerangue) é bastante pertinente neste contexto, pois faz referência a escolhas consideradas, a priori, positivas para o meio ambiente, mas quando implementadas geram novas implicações. Cada avanço tecnológico que surge com a finalidade de ampliar a ecoeficiência de produtos, automaticamente traz a nova oportunidade de consumo, ampliando assim a insustentabilidade no contexto aplicado (MANZINI, 2008).

Outra questão importante está relacionada com a facilidade crescente de acesso às manufaturas de Fabricação Digital, pela rápida disseminação e custos relativamente baixos para a aquisição tanto dos equipamentos, serviços e softwares (CACCERE, 2017). Um fator que auxilia essa difusão é a capacidade de auto-replicação, fazendo referência as manufaturas aditivas (BALLERINI, 2017). Porém, isso implica na questão do uso responsável da tecnologia, uma vez que pessoas "leigas" têm o poder do uso da máquina para a fabricação do que desejar, tendo disponíveis em sites projetos modelados prontos, disponíveis gratuitamente para a produção (ou seja, os chamados open-design ou open-source design).

O termo open-source (código aberto) é definido como 'manufatura distribuída', com acesso livre aos arquivos de produtos digitais, cujos principais atores são os consumidores. Ademais, tais arquivos podem ser configuráveis e adaptados para atender as principais necessidades do público consumidor. Esse modelo do open-design altera o paradigma da relação desenvolvedor-fabricante-distribuidor-consumidor, criando uma relação direta entre desenvolvedores e consumidores (AVITAL, 2011).

A produção autônoma, porém, entendida como produção doméstica, possui como público alvo amadores, mas pode ocasionar preocupações em relação ao consumismo (BALLERINI, 2017), em virtude do acesso aos projetos para a fabricação livre.

No cenário dos impactos ambientais, destacam-se as questões de fabricação de objetos com geometrias complexas (características da fabricação digital), em máquinas de manufatura subtrativa. Por mais planejado seja o corte de peças (uso de plug-in RhinoNest ${ }^{\mathrm{a}}$ ), o fato dos projetos conterem variadas curvas pode resultar em um grande volume de resíduos pequenos, inviabilizando seu reaproveitamento e, consequentemente, provocando danos ambientais, tanto pelo material inutilizado quanto pelo descarte incorreto, em muitos casos.

\footnotetext{
${ }^{a}$ RhinoNest é um plug-in usado junto ao software de modelagem Rhino, que tem como função a geração do planejamento de corte.
} 
Figura 2 - Planejamento de corte

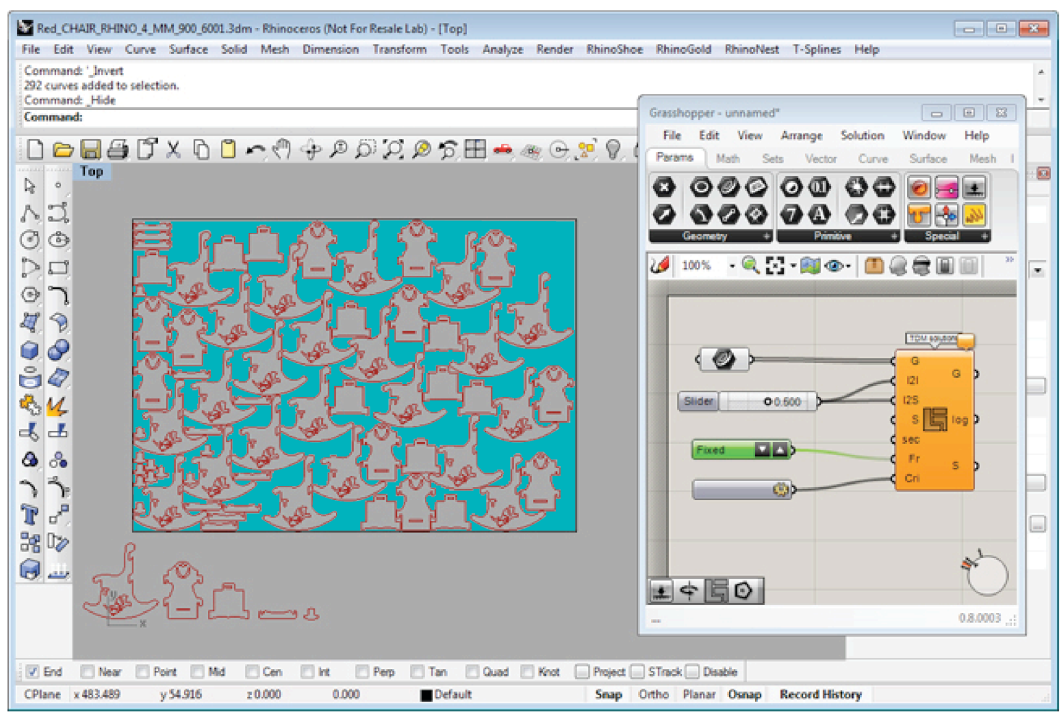

Fonte: Autor (2018)

No caso da máquina 3D, com manufatura aditiva, um dos problemas mencionados na literatura é a facilidade de plágio de produtos sem devida autorização e até o uso da tecnologia para criar produtos ilegais, tais como armas de fogo (CACCERE, 2017).

Kohtala (2014) ainda menciona outra questão relevante: o estímulo ao aumento do consumo. Dessa forma, o aumento de fabricação de novas categorias de produtos implicaria, necessariamente, o sistema de reciclagem do consumidor como, por exemplo, do material plástico, o que pode ocorrer pelas propriedades dos materiais e até mesmo barreiras ocasionadas por mudanças de hábitos.

Entende-se então, que o uso dessas novas máquinas deve ser consciente, ou seja, demanda um compromisso para o 'projetar responsável', evitando implicações futuras. De acordo com Mitchel (KOLAREVIC, 2005), há uma grande distinção de comportamento dos profissionais do século $X X$ e no século $X X I$, no qual o profissional tenta desenvolver sua competência até o ponto de assumir mais riscos. Para o autor, o que define um profissional é a capacidade de entrar em situações nas quais consegue lidar com os fatores de riscos envolvidos, buscando uma mudança de paradigma na atitude dos profissionais em geral (KOLAREVIC, 2005).

Apesar do conhecimento dos softwares de modelagem, utilizados em seus processos de projetos, os projetistas ainda não estão preparados para solucionar questões relativas à produção, tais como parâmetros da Fabricação Digital (BARBOSA NETO et al., 2014). Destaca-se também a importância de uma especialização de qualidade do designer em relação a fabricação digital e de sua adequação aos recentes processos de fabricação (BALLERINI, 2017).

As etapas de projeto estão associadas à metodologia escolhida para desenvolvê-lo. Atualmente, existem diversas metodologias disponíveis para auxiliar o designer nesse processo. A metodologia tem como ponto chave a responsabilidade de fornecer as ferramentas necessárias para o aperfeiçoamento do processo de projeto e está condicionada à complexidade do problema em questão (BURDEK, 1999 apud BARROS, 2011).

Umas das técnicas consideradas relevantes no campo de design de produtos, abordada nas diversas metodologias convencionais é a análise de soluções existentes, para contribuir a concepção de novos produtos (BARROS, 2011). Devido à complexidade da fabricação digital que 
interage com o usuário, o designer é interpretado como solucionador de problemas através da criação de propostas, que demandam entendimento, habilidades e domínio cada vez mais avançado em relação às novas tecnologias.

Nesse contexto, a ideia de experimentação associa o design à fabricação digital, desde os primeiros estágios, introduzindo não somente teorias, mas também metodologias, conhecimento e ferramentas para estimular o pensar e fazer, promovendo, então, não somente o domínio das ferramentas mas também a sua integração (FROGHERI, 2016).

Levando em consideração estas questões, a pesquisa visa desenvolver diretrizes projetuais para a Fabricação digital para minimizar os resíduos gerados na fabricação subtrativa. Essas estratégias são de extrema importância para diminuir o impacto ambiental que os processos de fabricação em geral e os produtos finais vêm causando, em busca de soluções mais sustentáveis.

De modo ampliado, as estratégias de projeto devem buscar o equilíbrio entre a liberdade criativa e o processo de fabricação, sendo guiadas pela responsabilidade e ética projetual. Em uma entrevista com o designer Charles Eames, sobre os conceitos da exposição Qu'est-ce le design? (O que é Design?) em 1972, Eames afirma que há sempre restrições de Design, e que tais implicam em uma ética (DESIGN Q \& A, 1972). Em um dos questionamentos sobre quais seriam essas restrições, Eames responde:

\begin{abstract}
"A soma de todas as restrições. Aqui está uma das poucas chaves eficazes para o problema de Design: a capacidade do Designer de reconhecer o maior número possível de restrições; sua vontade e entusiasmo por trabalhar dentro dessas restrições. Restrições de preço, de tamanho, de força, de equilíbrio, de superfície, de tempo e assim por diante. Cada problema tem sua própria lista peculiar" (Trecho da entrevista, tradução livre, DESIGN Q \& A, 1972).
\end{abstract}

Em sua essência, o design possui a liberdade de criação; mas essa liberdade também deve ter em mente as várias restrições mencionadas. Quando se discute diretrizes projetuais, busca-se atuar dentro da ética profissional ligada ao meio ambiente, em busca do aprendizado social que deve ser intrínseco a todos os indivíduos, principalmente aos projetistas.

Alcançar um processo de criação que avança nas questões culturais e sociais seguindo o viés sustentável, demanda do design sua desvinculação de quesitos somente estético-culturais. Depende das condições técnico-econômicas da fabricação em série e de um retorno consciente ao modelo inicial do ofício, que se preocupava com as questões éticas aplicadas ao processos de desenvolvimento e implementação de artefatos. Estas questões baseiam-se, essencialmente, em estudos dos fatores humanos, tecnológicos, econômicos, buscando a melhoria na qualidade de vida e a preservação ambiental (CASAGRANDE JR., 2004 apud SILVA; HEEMANN, 2008).

\title{
4 Considerações Finais
}

A partir deste panorama foi possível perceber que as novas manufaturas digitais contribuem fortemente para avanços no campo de design, no entanto, a partir do uso equivocado dessas maquinas, podem ocasionar sérios riscos ambientais, principalmente direcionados às questões de geração e gestão de resíduos. Diante disso, é de urgência necessidade a busca do aprendizado social, enfatizando a importância do direcionamento na etapa projetual em busca de soluções mais eficazes e sustentáveis.

As estratégias e diretrizes de projeto mencionadas devem, portanto, buscar o equilíbrio entre a liberdade de criação e o processo de fabricação, sendo orientadas pela responsabilidade e ética projetual relacionada ao meio ambiente. Estas diretrizes são extremamente importantes para direcionar os projetistas na etapa de criação e fabricação, em busca de configurar um novo 70 SDS $_{2019}^{\mathrm{RECIFE}}$ 
modelo de projetar contemporâneo, o 'projetar sustentável'.

Deve se então, buscar o compromisso de 'projetar responsável', antevendo e evitando danos ambientais, em busca de soluções mais sustentáveis e eco eficientes, minimizando o máximo de resíduos em etapas de manufaturas e aumentando a sustentabilidade na produção.

\section{Referências}

AVITAL, M. The Generative Bedrock of Open Design. In: B. Van Abel; R. Klaassen; L. Evers; P. Troxler (Eds.); Open Design Now: Why Design Cannot Remain Exclusive, 2011. Amsterdam: BIS Publishers. Disponível em: <http://opendesignnow.org/>. Acesso em: 20 abr. 2018.

BALLERINI, Flávia. FABRICAÇÃO DIGITAL: UMA ANÁLISE CRÍTICA -FORTALECENDO A COOPERAÇÃO POR MEIO DA FABRICAÇÃO DIGITAL. 2017. 274 f. Tese (Doutorado) - Curso de Arquitetura, Universidade Federal de Minas gerais, Belo Horizonte, 2017.

BARBOSA NETO, W.et al. Samba reception desk: Compromising aesthetics, fabrication and structural performance with the use of virtual and physical models in the design process. Gestão e Tecnologia de Projetos, São Paulo, v. 9, n. 2, p.53-69, jul./dez. 2014. http://dx.doi.org/10.11606/gtp.v9i1.83913

BARROS, Alexandre Monteiro de. Fabricação digital: sistematização metodológica para o desenvolvimento de artefatos com ênfase em sustentabilidade ambiental. 2011. $102 \mathrm{f}$. Dissertação (Mestrado) - Curso de Design, Universidade Federal do Rio Grande do Sul, Porto Alegre, 2011.

BLIKSTEIN, P.(2013). Digital Fabrication and 'Making' in Education: The Democratization of Invention. In: J. Walter-Herrmann \& C. Büching (Eds.), FabLabs: Of Machines, Makers and Inventors. Bielefeld: Transcript Publishers.

CACCERE, João Paulo Amaral. Fabricação digital como abordagem para a produção e design distribuídos. 2017. 267 f. Dissertação (Mestrado) - Curso de Design, Universidade Federal do Paraná, Curitiba, 2017.

DESIGN Q \& A. Interview with Charles Eames. [s. L.]: Musée Arts Decoratifs, 1972. P\&B. Disponível em: <https://www.youtube.com/watch?v=3xYi2rd1QCg>. Acesso em: 02 jan. 2019.

FROGHERI, Daniela; ESTÉVEZ, Alberto T. Entre el pensar y el hacer avanzados: Between the advanced thinking and the advanced making. In: XX CONGRESO DE LA SOCIEDAD IBEROAMERICANA DE GRÁFICA DIGITAL, 20., 2016, Buenos Aires. Anais... . Buenos Aires: ESARQ, 206. p. $219-226$.

GERHARDT, Tatiana Engel; SILVEIRA, Denise Tolfo (Org.). Métodos de pesquisa. Porto Alegre: Ufrgs, 2009. $120 \mathrm{p}$.

HAUSCHILD, Moritz; KARZEL, Rudiger. Digital Processes. Munich: Detail, 2011. 111 p.

KOHTALA, C. Addressing sustainability in research on distributed production: an integrated literature review. Journal of Cleaner Production, v. 92. 2014.

KOLAREVIC, Branko (Ed.). Architecture in the digital age: design and manufacturing. New York: Taylor e Francis, 2005. 314 p.

MANZINI, E. Cenários da Matéria. In CALÇADA, A.; MENDES, F.; BARATA, M. (coords.) Design em Aberto: uma antologia. Porto: Bloco Gráfico Ltda. 1993. p.139-143.

MANZINI, E.; VEZZOLI, C. O desenvolvimento de produtos sustentáveis: os requisitos ambientais 
dos produtos industriais. São Paulo: EDUSP. 2008.

MANZINI, Ezio. Design para a inovação social e sustentabilidade: Comunidades criativas, organizações colaborativas e novas redes projetuais. Rio de Janeiro: E-papers, 2008. 103 p. Tradução de Carla Cipolla.

MEREDITH, Michael. From control to design: parametric/algorithmic architecture. New York: IngoprintSt, 2008. 239 p.

NUNES, Viviane G. A. Design sustentável: [im] possível?. In CASTRO, M.L.; NUNES, Viviane G.A. (orgs) Os desafios projetuais na construção da sustentabilidade: Desafios projetuais: ecologia e sustentabilidade. Uberlândia: JT Soluções Gráficas Ltda/UFU, 2008. 110 p.

OOSTERHUIS, K. File to Factory and Real Time Behavior in ONL-Architecture. 2005. Disponível em: < http://papers.cumincad.org/data/works/att/acadia04_294.content.pdf> Acesso em: 20 outubro 2018.

ORCIUOLI, Affonso. Marcenaria Digital:: design e fabricação sustentável. In: SIGRADI 2012 | FORMA (IN) FORMAÇÃO, 1., 2012, Fortaleza. Proceedings.... Fortaleza: Sigradi, 212. p. 653 - 656.

OXMAN, R. Theory and design in the first digital age. Design Studies, v. 27, n.3, p.229-265, 2006. http://dx.doi.org/10.1016/j.destud. 2005.11.002

PUPO, Regiane Trevisan. Inserção da PROTOTIPAGEM e FABRICAÇÃO DIGITAIS no processo de projeto: um novo desafio para o ensino de arquitetura. 2009. 259 f. Tese (Doutorado) - Curso de Engenharia Civil, Universidade Estadual de Campinas, Campinas, 2009.

SEELY, Jennifer Ck. DIGITAL FABRICATION IN THE ARCHITECTURAL DESIGN PROCESS. 2004. $77 \mathrm{f}$. Dissertação (Mestrado) - Curso de Arquitetura, Massachusetts Institute Of Technology, Cambridge, 2004.

SILVA, Jucelia S. Giacomini da; HEEMANN, Ademar. ECO-CONCEPÇÃO: DESIGN, ÉTICA E SUSTENTABILIDADE AMBIENTAL. In: I ENCONTRO DE SUSTENTABILIDADE EM PROJETO DO VALE DO ITAJAÍ, 1., 2007, Vale do Itajaí. Anais... . Vale do Itajaí: Ensus, 2008. p. 1 - 18

THIOLLENT, Michel. Metodologia da Pesquisa-Ação. São Paulo: Cortez,1985. 